\title{
A new SERS substrate based on niobium lead-pyrophosphate glasses obtained by $\mathrm{Ag}^{+} / \mathrm{Na}^{+}$ion exchange
}

\author{
Danilo Manzani $^{\mathrm{a}, *}$, Douglas F. Franco ${ }^{\mathrm{b}}$, Conrado R.M. Afonso ${ }^{\mathrm{c}}$, Antônio C. Sant'Ana ${ }^{\mathrm{d}}$, \\ Marcelo Nalin ${ }^{\mathrm{b}}$, Sidney J.L. Ribeiro ${ }^{\mathrm{b}}$ \\ ${ }^{a}$ São Carlos Institute of Chemistry - IQSC, University of São Paulo - USP, São Carlos, SP, Brazil \\ ${ }^{\mathrm{b}}$ Institute of Chemistry, São Paulo State University - UNESP, Araraquara, SP, Brazil \\ ${ }^{c}$ Materials Engineering Department - DEMA, Federal University of São Carlos - UFSCar, São Carlos, SP, Brazil \\ d Department of Chemistry, Federal University of Juiz de Fora - UFJF, Juiz de Fora, MG, Brazil
}

\section{A R T I C L E I N F O}

\section{Keywords:}

Phosphate glass

Ion exchange

SERS

Raman spectroscopy

Trace analysis

\begin{abstract}
A B S T R A C T
Surface-enhanced Raman scattering (SERS) is one of the most sensitive methods for the detection of adsorbed molecules on the nanostructured coinage-metal surface. The enhancements in the order of $10^{4}-10^{6}$ are routinely observed. Such an effect makes SERS spectroscopy a technique applicable to the study the adsorption of analytes in the submonolayer regime. Novel SERS sensors require novel substrates with high activity for great sensibility detection of different molecules applied in many fields, such as detections of narcotics, explosives, and molecules with biological interest. In this work, silver nanoparticles embedded in niobium lead-pyrophosphate glasses $\left(\mathrm{Pb}_{2} \mathrm{P}_{2} \mathrm{O}_{7}-\mathrm{Nb}_{2} \mathrm{O}_{5}-\mathrm{Na}_{2} \mathrm{O}\right)$ were prepared by ion exchange process, where silver ions were introduced into glass surface by $\mathrm{Ag}^{+} / \mathrm{Na}^{+}$ion exchange $\left(\mathrm{NaNO}_{3}: \mathrm{AgNO}_{3}\right.$ batch), and reduced to metallic silver by heat treatment at glass transition temperature (ca. $480^{\circ} \mathrm{C}$ ). The new substrate was characterized by Raman spectroscopy, optical absorption, transmission electron microscopy (TEM) and atomic force microscopy (AFM). Its application in SERS was demonstrated by studying the adsorption of 2,2-bipyridine (bpy) on the glass surface, which has marker bands for the coordination of the adsorbate with silver atoms. The optimal surface features in terms of SERS enhancement were also discussed and the sensing ability of this new substrate was demonstrated.
\end{abstract}

\section{Introduction}

Glasses containing gold, silver or copper nanoparticles (NP) are promising materials for several plasmonic applications because their interesting optical properties ascribed to their localized surface plasmon resonance (LSPR) transitions [1,2]. The LSPR absorption frequency of such metals are commonly observed in the visible and near infrared region and assigned to the coherent oscillation of electrons in the conduction band when excited with an electromagnetic radiation $[3,4]$. Scientific research in plasmonic materials has attracted large attention due to their promising application in advanced biomolecule sensing [5], chemical detection [6], cancer treatment [7], plasmonic solar cells [8] and other practical applications in material science [9].

Phosphate glasses are good candidates for technological and optical applications due to their intrinsic characteristics, such as low melting point $\left(\mathrm{T}_{\mathrm{m}}\right)$, viscosity and glass transition temperatures $\left(\mathrm{T}_{\mathrm{g}}\right)$, large thermal stability against crystallization, broad transparency from ultraviolet to infrared region, and higher thermal expansion coefficient when compared with silicate glasses [10-12]

Surface-enhanced Raman spectroscopy (SERS) is a highly sensitive technique for trace analysis (concentrations from $10^{-5}$ to $10^{-7} \mathrm{M}$ ) [13-16] and is based mainly on the LSPR effect. The SERS spectrum of the target analyte is amplified through the excitation of the LSPR of the substrate containing dispersed metallic NP or a nanostructured metal film. Following the discovery of the SERS phenomenon by Fleischmann et al. it has become a promising and attractive subject in surface-sensitivity research and nanoscience [17-19]. Consequently, SERS substrates are the protagonists on the enhancement of intensity by several orders of magnitude of the analytical signal [20]. Many types of research have been devoted to creating new SERS substrates presenting larger signal enhancements for the extremely low concentration of analytes. They have been widely applied in different research fields, such as biomaterials [21], sensors [22] and chemical detection [23].

Among metal NP presenting accessible LSPR effects, Ag-NPs are the

\footnotetext{
* Corresponding author at: University of São Paulo, São Carlos Institute of Chemistry - IQSC, Department of Chemistry and Molecular Physics, São Carlos, SP, Brazil.

E-mail address: dmanzani@usp.br (D. Manzani).
} 
most used metal due to their highly reactive surface for SERS [24]. In coordination chemistry, 2,2'-bipyridine (bpy) is widely utilized with transition metal ions, been studied for different applications such as electroluminescent devices [25,26], photocatalysis [27], solar cells [28] and biological investigations. Bpy is a bidentate ligand, forming complexes with metals by chelate effect [29]. In this study, the SERS spectra of bpy adsorbed on Ag-NPs, grown on the niobium-phosphate glasses surface, are reported. Glasses are versatile host to embed Ag-NP because it provides chemical stability for the metallic nanoparticles, which can be homogeneously obtained inside the glass volume or only superficially $[30,31]$.

Glasses containing metallic NP can be produced by different techniques such as ion implantation [32], femtosecond laser irradiation [33], sol-gel methods [34] and ion exchange processes [35]. Among them, ion-exchange techniques have widely been applied to develop special functional glasses for SERS chemical sensing, chemically tempered glasses [36-38] and planar waveguides [39]. Herein ion-exchange technique was used to incorporate silver ions into the glass matrix by diffusion. The samples were immersed into a fused salt bath containing $\mathrm{Na}^{+}$and $\mathrm{Ag}^{+}$ions, followed by thermal annealing to reduce $\mathrm{Ag}^{+}$in metallic Ag-NPs.

One of the most important requirements for plasmonic materials suitable for photonic applications, such as SERS, is to possess low linear and nonlinear losses, large third-order nonlinearities, good optical quality and mechanical strength and low dimensions [33,39]. Based on the aforementioned characteristics, niobium pyro-phosphate glasses containing Ag-NPs clusters on the surface shows highly potentiality for SERS applications to attempt the required conditions for plasmonic materials $[40,41]$. In this sense, the present work aims to fabricate a novel and reusable SERS substrate to be used in single-molecule detection. Ag-NPs were synthesized on the niobium pyro-phosphate glass surface through a single ion-exchange step of $\mathrm{Na}^{+} \leftrightarrow \mathrm{Ag}^{+}$, followed by nucleation/reduction processes of $\mathrm{Ag}^{+}$to $\mathrm{Ag}^{\circ}$ by thermal annealing. Then, the evaluation of SERS activity was demonstrated by exposing the substrate under the presence of bpy as an out-of-resonance analyte, showing the high potentiality for chemical sensing.

\section{Experimental}

\subsection{Glass synthesis and $\mathrm{Ag}^{+} / \mathrm{Na}^{+}$ion-exchange procedure}

The glass samples were synthesized by the conventional meltquenching method using the raw materials $\mathrm{Nb}_{2} \mathrm{O}_{5}$ (Aldrich 99.8\%) and lead orthophosphate $\mathrm{PbHPO}_{4}$ prepared by precipitation of a lead salt solution with pure orthophosphate acid at room temperature, as detailed described in [42]. Chemicals precursors were stoichiometrically weighted in order to obtain $20 \mathrm{~g}$ of composition $90\left[60 \mathrm{~Pb}_{2} \mathrm{P}_{2} \mathrm{O}_{7}-40 \mathrm{Nb}_{2} \mathrm{O}_{5}\right]: 10 \mathrm{Na}_{2} \mathrm{O}$ glass (labeled as PNN glass) and thermal treated before melting at $200{ }^{\circ} \mathrm{C}$ for $1 \mathrm{~h}$ to reduce adsorbed water and gases since the $\mathrm{PbHPO}_{4}$ is obtained via a wet chemical route. Then, the batch was melted under open air at $1000^{\circ} \mathrm{C}$ for $40 \mathrm{~min}$ to ensure homogenization and fining. Finally, the melt was cast inside a stainless steel preheated mold at $380^{\circ} \mathrm{C}$ and then annealed at the same temperature for $4 \mathrm{~h}$ to minimize mechanical stress resulting from thermal gradients upon cooling. Such procedure is important because it enhances the mechanical strength of glasses to support the ion-exchange temperature procedure avoiding cracks. The obtained glass sample was equally cut in 6 parts which were immersed into a fused salt molten of $\mathrm{NaNO}_{3}: \mathrm{AgNO}_{3}$.

The $\mathrm{Na}^{+}-\mathrm{Ag}^{+}$ion-exchange method was used to put into the glass surface $\mathrm{Ag}^{+}$which were the germs for growth Ag-NP onto glass sample surface after heat treatment. First, PNN glass pieces were previously cleaned with acetone and isopropyl alcohol, then immersed into a molten salt of $\mathrm{NaNO}_{3}: \mathrm{AgNO}_{3}$ (4:1), in platinum crucible, at $380{ }^{\circ} \mathrm{C}$ for $18 \mathrm{~h}$ in order to allow the diffusion of silver ions into the glass by replacing the $\mathrm{Na}^{+}$(glass) with $\mathrm{Ag}^{+}$(molten bath). After the ion-exchange
Table 1

Synthesis conditions and sample labels.

\begin{tabular}{llll}
\hline Sample labels & $\begin{array}{l}\text { Glass transition temperature, } \\
\mathrm{T}_{\mathrm{g}}\end{array}$ & $\begin{array}{l}\text { Step 1 } \\
\text { Ion-exchange }\end{array}$ & $\begin{array}{l}\text { Step 2 } \\
\text { Annealing }\end{array}$ \\
\hline PNN & $470 \pm 2{ }^{\circ} \mathrm{C}$ & - & - \\
PNN-Ag & $470 \pm 2{ }^{\circ} \mathrm{C}$ & $380^{\circ} \mathrm{C} / 18 \mathrm{~h}$ & $470{ }^{\circ} \mathrm{C} / 0 \mathrm{~min}$ \\
PNN2-Ag & & & $470{ }^{\circ} \mathrm{C} / 2 \mathrm{~min}$ \\
PNN5-Ag & & $470{ }^{\circ} \mathrm{C} / 5 \mathrm{~min}$ \\
PNN10-Ag & & $470{ }^{\circ} \mathrm{C} / 10 \mathrm{~min}$ \\
PNN20-Ag & & $470{ }^{\circ} \mathrm{C} / 20 \mathrm{~min}$ \\
\hline
\end{tabular}

procedure, the glass pieces were removed from the molten and cleaned with distilled water and acetone to remove the excess of $\mathrm{NaNO}_{3}$ and $\mathrm{AgNO}_{3}$ adhered on the surface. Thus, the as-exchanged samples were annealed in air at glass transition temperature, $T_{g}$, for 2, 5, 10 and $20 \mathrm{~min}$ in order to induce the formation of metallic Ag-NP on the PNN glass surface. Table 1 summarizes the synthesis conditions and sample labels.

\subsection{Glass characterizations}

Glass characteristic temperatures such as glass transition temperature, $T_{g}$, onset crystallization temperature, $T_{x}$, and maximum of crystallization peak, $T_{p}$, were obtained from differential scanning calorimetry in the range of 300 to $1000^{\circ} \mathrm{C}$ using a NETZSCH equipment DSC 404 F3 Pegasus calorimeter, with a maximum error of $\pm 2{ }^{\circ} \mathrm{C}$ for $T_{g}$ and $T_{x}$ (obtained from tangents intersection) and $\pm 1{ }^{\circ} \mathrm{C}$ for $T_{p}$. Glass pieces of about $12 \mathrm{mg}$ were set in opened platinum pans under $\mathrm{N}_{2}$ atmosphere and a heating rate of $10{ }^{\circ} \mathrm{C} / \mathrm{min}$.

Absorption spectra of the glass samples were acquired from 200 to $800 \mathrm{~nm}$ with a Varian Cary 5000 spectrophotometer. Raman scattering spectra were acquired at room temperature in the frequency range from 200 to $1800 \mathrm{~cm}^{-1}$ by using a HORIBA Jobin Yvon model LabRAM HR micro Raman apparatus equipped with CCD detector and a $632.8 \mathrm{~nm}$ laser line, delivering $30 \mathrm{~mW}$ power.

HR-TEM and SAED were performed in order to check the size and distribution of the grown $\mathrm{Ag}-\mathrm{NP}$ and their nature, by using powdered glasses suspended in ethanol and deposited on grids in an FEI, Model Tecnai G2 F20 (200 kV) microscope equipped with a field emission gun.

Atomic force microscopy (AFM) images were acquired by using an Agilent AFM system (model 5500) in tapping mode in the air and using a Si tip with aluminum coating on the back for reflection. Typical settings: tip curvature radius $<10 \mathrm{~nm}$, cantilever length of $125 \mu \mathrm{m}$, the width of $30 \mu \mathrm{m}$, the constant force of $42 \mathrm{~N} \mathrm{~m}^{-1}$ and resonant frequency at $320 \mathrm{kHz}$. The AFM phase and 3D topography images were obtained using the software Gwyddion V. 2.37.

\subsection{SERS procedure}

The SERS spectra for the bpy adsorbed in the PNN2-Ag glass substrate were acquired in a Raman Spectrometer LabRam HR (Horiba Jobin-Yvon) equipped with a liquid nitrogen cooled CCD-camera (Horiba) and connected to a microscope (Olympus) with a 50X objective (WD). The SERS and Raman spectra were performed using $632.8 \mathrm{~nm}$ line of a He-Ne laser as excitation source delivering $30 \mathrm{~mW}$ of power and accumulation time of $200 \mathrm{~s}$. Concomitantly, the line in 520 $\mathrm{cm}^{-1}$ in the Raman spectrum of silicon was used aiming frequency calibration and the accuracy of the spectral measurements. The excitation light was directed onto the sample and the collection of the backscattered light was done at $180^{\circ}$ geometry as schematically shown in Fig. 1.

The SERS spectra of bpy were obtained after the immersion of PNN2-Ag in a bpy solution $\left(10^{-6} \mathrm{M}\right)$ for $40 \mathrm{~min}$. After this procedure, the substrate was washed with deionized water (milli-Q pattern) and subsequently dried to obtain SERS spectra. The same method was 


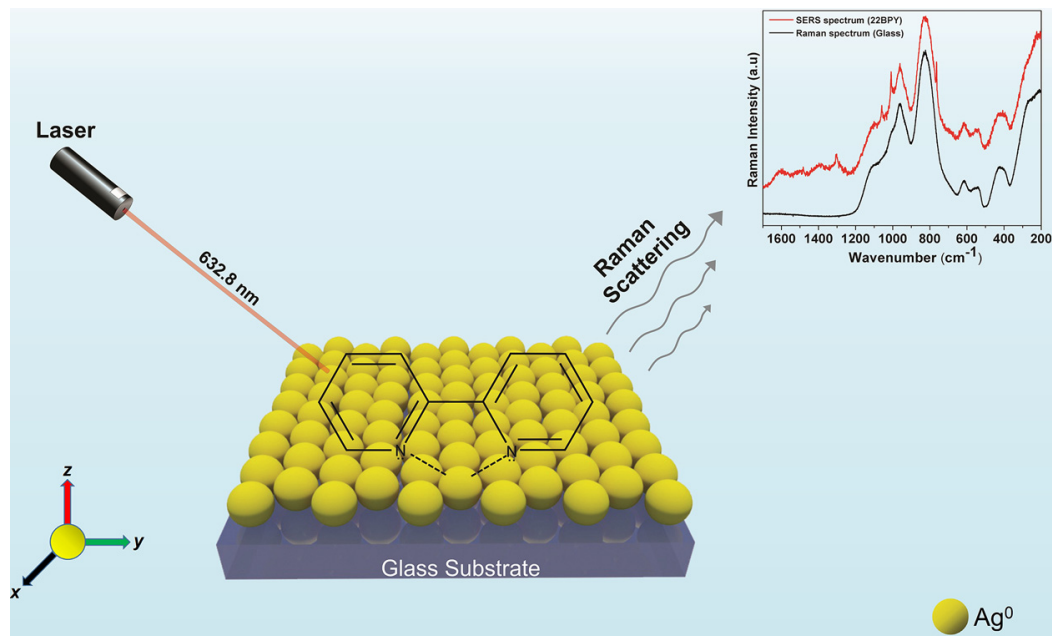

Fig. 1. Schematic figure of SERS procedure used with PNN2-Ag sample. The yellow balls indicate atoms of metallic silver $\left(\mathrm{Ag}^{\circ}\right)$. At the bottom left side the Cartesian axis helps to identify the perpendicular position (z-axis) of bpy molecule in the relation of the glass surface through nitrogen atoms coordination with silver atoms (For interpretation of the references to colour in this figure legend, the reader is referred to the web version of this article).

performed for the PNN2 substrate without $\mathrm{Ag}$ nanoparticles. The average SERS spectrum displayed on the inset of Fig. 1 was the result of the sum of 10 Raman spectra obtained at different regions of the PNN2Ag glass surface over an area of ca. $10^{4} \mathrm{~mm}^{2}$.

\section{Results and discussion}

X-ray diffraction shows the typical amorphous halo for all samples presented in Table 1. No diffraction peaks are observed regardless of the time of annealing because the concentration of Ag-NP is below to the technique detection limit. As expected, DSC curves showed the same thermal behavior for all glass samples and the characteristics temperatures $T_{g}, T_{x}$, and $T_{p}$ are unchanged at $470{ }^{\circ} \mathrm{C}, 590{ }^{\circ} \mathrm{C}$ and $640{ }^{\circ} \mathrm{C}$, respectively. Based on X-ray diffractograms and DSC analysis, the thermal annealing used to growth Ag-NP on the samples surfaces, not caused abrupt glass structural modifications independently of the annealing time undergone for each sample.

On the other hand, the thermal annealing after the ion-exchange procedure causes significant changes in the sample colors. PNN sample, which was ion-exchanged without thermal annealing, shows a homogeneous yellowish color, transparent and free of strains. However, the annealed samples become brownish as a function of annealing time, and a thin mirrored film was formed on sample surfaces as shown in Fig. 2. Generally, materials containing metallic NP shows an intense color-dependence upon both size and concentration of the particles, as well as the refractive index of the surrounding medium [43-46].

Barbosa et al. [47] reported the preparation and characterization of planar waveguides by using the $\mathrm{Na}^{+}-\mathrm{Ag}^{+}$ion-exchange process to modify the refractive index of an $\mathrm{Er}^{3+}$-doped $\mathrm{NaPO}_{3}-\mathrm{Nb}_{2} \mathrm{O}_{5}$ glass system. Therefore, the low concentration of $1 \mathrm{~mol} \%$ of $\mathrm{AgNO}_{3}$ was used to prevent the precipitation of Ag-NP, oppositely in our work where the

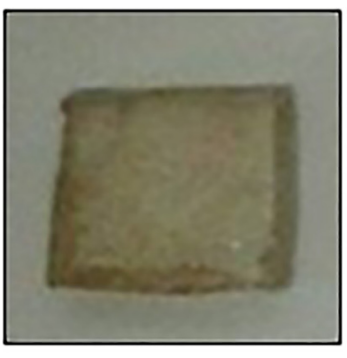

PNN-Ag

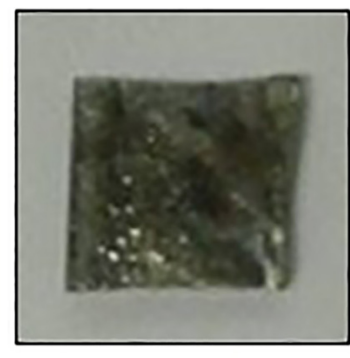

PNN5-Ag

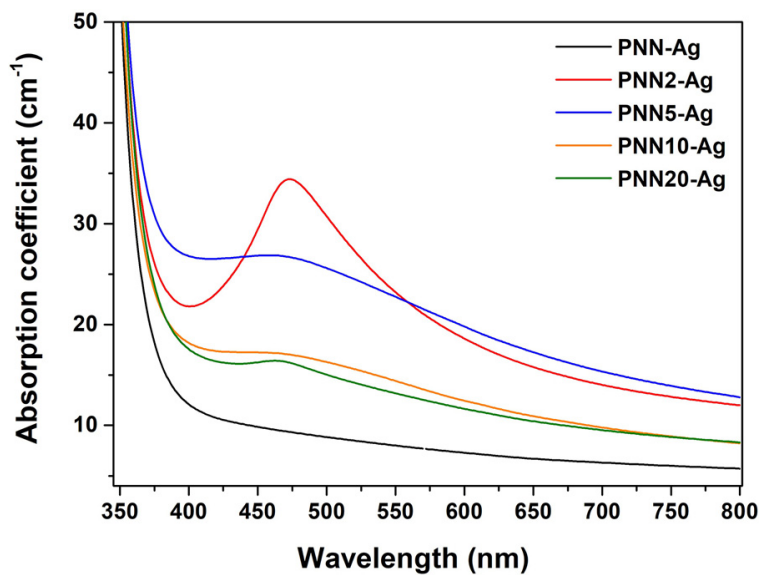

Fig. 3. Absorption spectra of the PNN glass samples without and with Ag, after heat treatment at different times of 2, 5, 10 and $20 \mathrm{~min}$.

concentration of $\mathrm{AgNO}_{3}$ was 20 times higher in order to drive as much as possible the exchange of $\mathrm{Ag}^{+}$by $\mathrm{Na}^{+}$containing into the glass network surface.

Fig. 3 shows the absorption spectra for the thermally annealed glass samples presented in Table 1 from $350 \mathrm{~nm}$ to $800 \mathrm{~nm}$, at room temperature. The LSPR absorption band is observed for all glass samples, except for PNN due to the absence of Ag-NP. The LSPR absorption band from PNN2-Ag is much higher and narrower compared to the other samples due to the homogeneous formation of small silver nanoparticles with a narrow size distribution induced by the low growth rate because of the rapid annealing time applied for this sample. An abrupt decreasing of LSPR band intensities are observed for PNN5-Ag, PNN10-

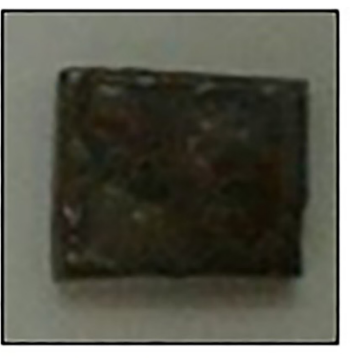

PNN10-Ag

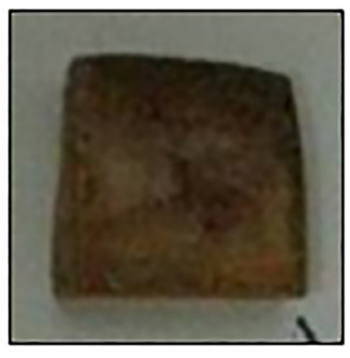

PNN20-Ag

Fig. 2. Photographs of the glass samples after thermal annealing at $T_{g}$ for $0,5,10$ and 20 min to induces Ag-NP growing onto the glass surfaces. 

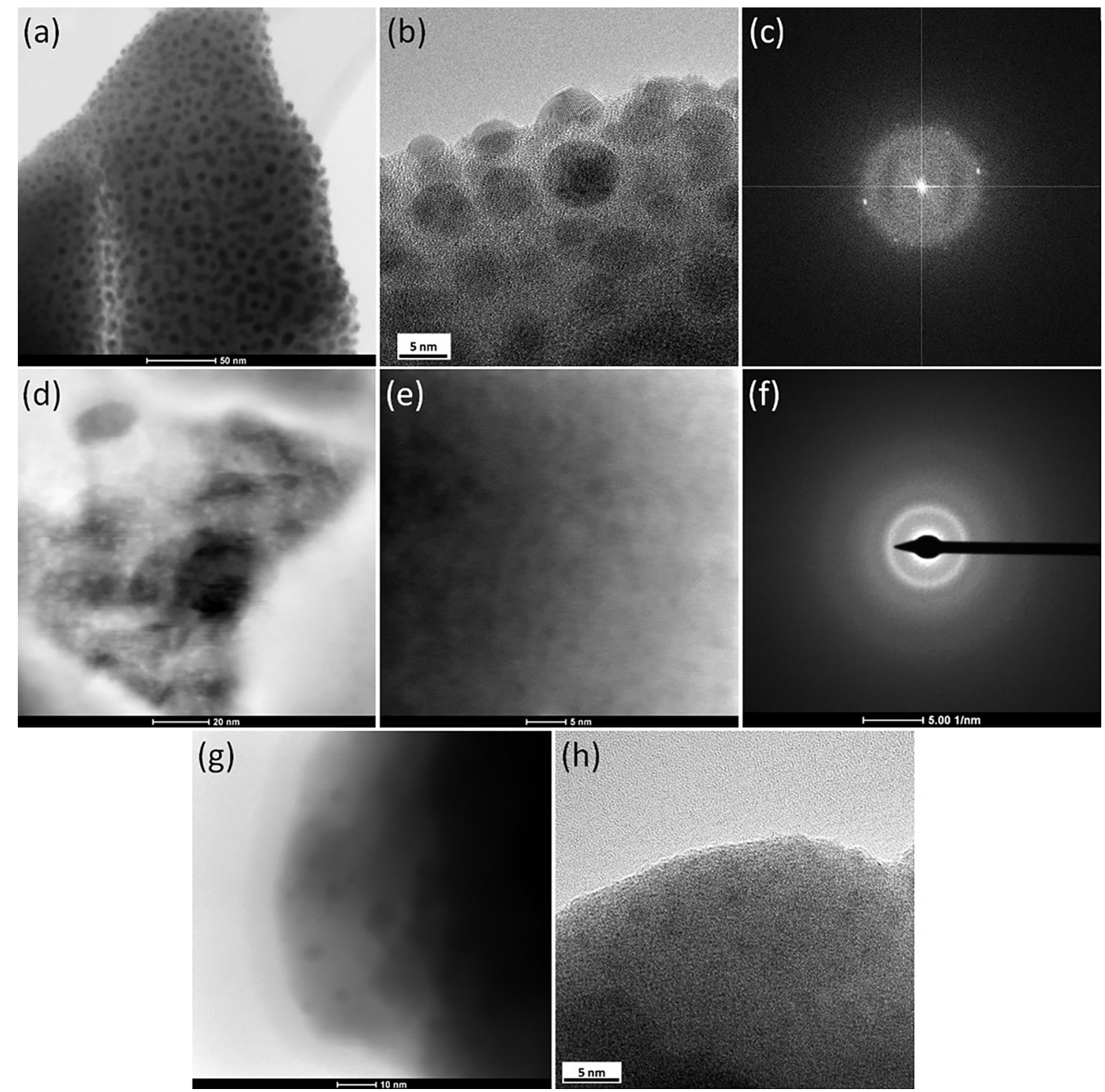

Fig. 4. Transmission electron microscopy images and SAED patters for PNN2-Ag sample (a, b and c), PNN10-Ag (d, e and f), and PNN20-Ag (q and h, without SAED pattern).

$\mathrm{Ag}$ and PNN20-Ag samples, suggesting that the increase of annealing time is reducing the amount of Ag-NP grew during the heat treatment. It suggests the annealing time above 2 min led to the formation of smaller nanoparticles than those obtained for PNN2-Ag samples. This fact is clearly observed through TEM images in Fig. 4. In fact, the absence of a shift in the maximum intensity of the LSPR band in respect to the annealing time, strongly indicates that there is no increase in the size of the Ag-NP [48]. On the other hand, if we expected an increase in the LSPR intensity, we are also expecting the increase of the number of Ag-NP possessing the same nanoparticle sizes. Interestingly, since we only observed a decrease of LSPR band intensity, it indicates that the Ag-NP are not growing in size with the time of annealing, but re-dissolving within the glass host.

TEM images in Fig. 4 clearly show that PNN2-Ag sample presents a homogeneous distribution of Ag-NP with a particle size of about 5 to $10 \mathrm{~nm}$ (Fig. 4a and b). Fig. 4c shows the SAED pattern to prove the nanoparticle chemical nature of metallic silver. Confronting the TEM images with the absorption spectrum of PNN2-Ag sample in Fig. 3, it is clear that the nature of the LSPR band is coming from the resonance of small Ag-NP obtained at a short annealing time. As the annealing time increases to $10 \mathrm{~min}$ and $20 \mathrm{~min}$, the Ag-NP pattern obtained for PNN2$\mathrm{Ag}$ is dismantling and the good distribution of the spherical Ag-NP is lost for the PNN10-Ag and PNN20-Ag samples. This behavior suggests that during long annealing times (10 and $20 \mathrm{~min}$ ), with the use of high $\mathrm{Ag}^{+}$concentration of the molten salt solution, the continuation of $\mathrm{Ag}^{+}$ diffusion toward to glass volume takes place, rather than promotes the aggregation and subsequent precipitation of Ag-NP. As observed through the images in Fig. 4d and e for PNN10-Ag sample, and Fig. $4 \mathrm{~g}$ and $\mathrm{h}$ for PNN20-Ag, this trend results in the formation of regions riches in silver (black regions) not formed by the clustering of metallic Ag nanoparticles. Fig. $4 \mathrm{f}$ shows the absence of diffraction in the SAED pattern for PNN10-Ag sample, which shows the low concentration of Ag-NP evidenced only by the presence of LSPR in the absorption spectra but undetected through selected area diffraction.

Fig. 5 illustrates the 3D topographic and AFM phase angle contrast of PNN2-Ag sample. The sample surface presents a medium surface roughness and a homogeneous topography with the maximum thickness of $0.44 \mu \mathrm{m}$. It is observed a homogeneous distribution of $\mathrm{Ag}$ clusters over the glass surface. The related roughness cannot be distinguished if it is from the glass surface or formed due to the uncontrolled growth of Ag-NP over the PNN2-Ag after thermal annealing.

In this sense, based on the previous results and discussion, PNN2-Ag sample was chosen to be used as a new SERS substrate by checking their potentiality for SERS applications in detection of the extremely low 

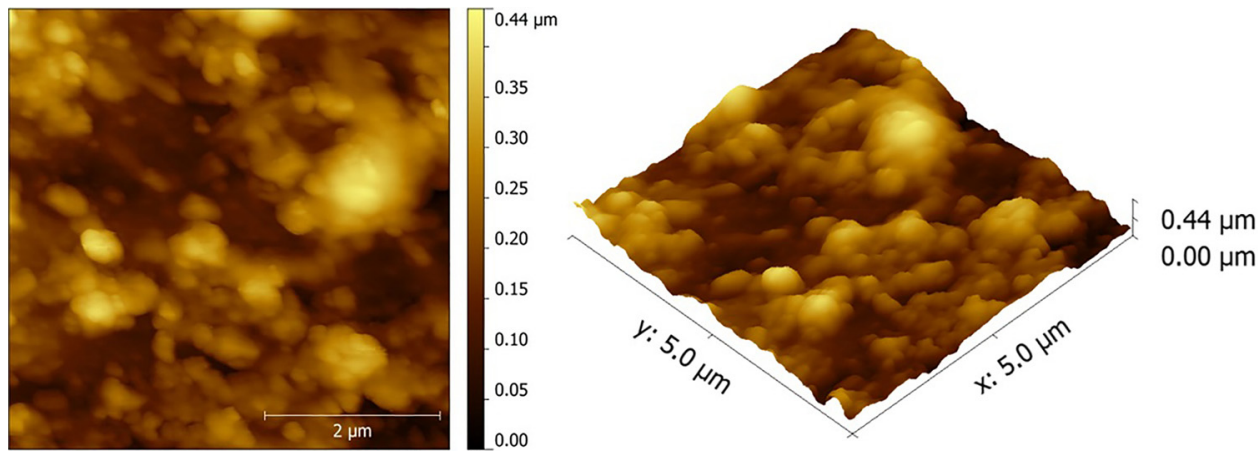

Fig. 5. Atomic force microscopy image of PNN2-Ag glass sample surface showing Ag-NP nanoparticles distribution over the surface.

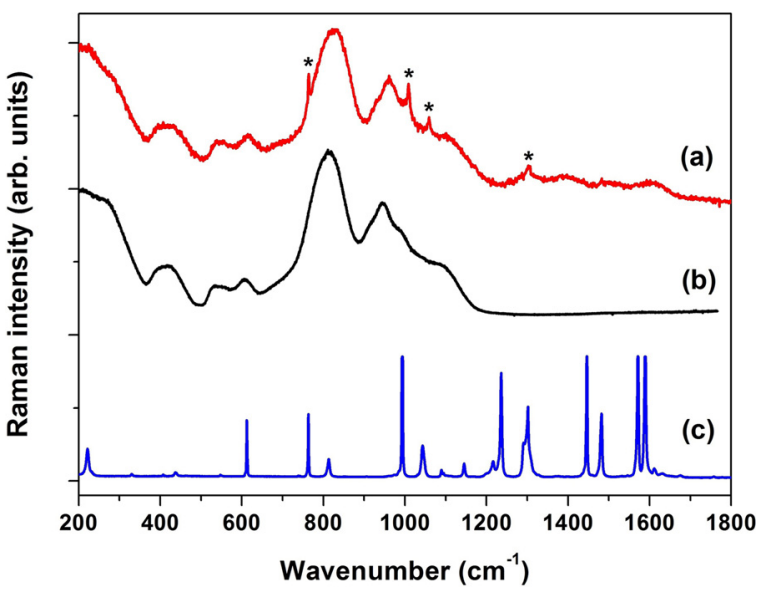

Fig. 6. SERS spectrum of bpy adsorbed on PNN2-Ag substrates assigned with an asterisk (a), Raman spectra of the PNN2 glass substrate (without Ag) after exposition to a bpy $\left(10^{-6} \mathrm{M}\right)$ aqueous solution (b) and bpy in the solid state (c) using excitation radiation in $632.8 \mathrm{~nm}$.

Table 2

Assignment of the observed Raman bands from bpy, and PNN2-Ag glass substrates in wavenumbers $\left(\mathrm{cm}^{-1}\right)$.

\begin{tabular}{|c|c|c|c|}
\hline $\begin{array}{l}\text { bpy } \\
\text { (solid) }\end{array}$ & $\begin{array}{l}\text { PNN2-Ag } \\
\text { substrate }\end{array}$ & $\begin{array}{l}\text { Ag-bpy surface } \\
\text { complex }\end{array}$ & Assignment \\
\hline 1589 vs & - & & $\nu(\mathrm{C}-\mathrm{C}, \mathrm{C}-\mathrm{N})+\delta(\mathrm{N}-\mathrm{H})$ \\
\hline 1571 vs & - & & $v(\mathrm{C}-\mathrm{C}, \mathrm{C}-\mathrm{N})$ \\
\hline $1481 \mathrm{~s}$ & - & 1482 & $\nu(\mathrm{C}-\mathrm{C}, \mathrm{C}-\mathrm{N})+\delta(\mathrm{C}-\mathrm{H})$ \\
\hline $1445 \mathrm{~s}$ & - & & $\nu(\mathrm{C}-\mathrm{C}, \mathrm{C}-\mathrm{N})+\delta(\mathrm{C}-\mathrm{H})$ \\
\hline $1307 \mathrm{~m}$ & - & & \\
\hline $1300 \mathrm{~s}$ & - & 1304 & $\begin{array}{l}\nu(\mathrm{C}-\mathrm{C}) \text { ir }+\nu(\mathrm{C}-\mathrm{C}, \mathrm{C}-\mathrm{N})+/ \\
\delta(\mathrm{C}-\mathrm{H})\end{array}$ \\
\hline $1236 \mathrm{~s}$ & - & & $\begin{array}{l}\nu(\mathrm{C}-\mathrm{C}, \mathrm{C}-\mathrm{N})+v(\mathrm{C}-/ \mathrm{C}) \mathrm{ir}+ \\
\delta(\mathrm{C}-\mathrm{H})\end{array}$ \\
\hline & 1115 & & $\nu_{\mathrm{s}}\left(\mathrm{PO}_{2}\right)$ \\
\hline $1092 \mathrm{w}$ & & & $\delta(\mathrm{C}-\mathrm{H})+\nu(\mathrm{C}-\mathrm{C}, \mathrm{C}-\mathrm{N})$ \\
\hline $1044 \mathrm{~m}$ & 1006 & 1059 & $\begin{array}{l}\delta(\mathrm{C}-\mathrm{H})+/ \nu(\mathrm{C}-\mathrm{C}, \mathrm{C}-\mathrm{N}) \\
\nu_{\mathrm{s}}\left(\mathrm{PO}_{3}\right)^{2-}\end{array}$ \\
\hline 993 vs & & $\begin{array}{l}1009 \\
962 \mathrm{br}\end{array}$ & $\begin{array}{l}\nu(\mathrm{C}-\mathrm{C}, \mathrm{C}-\mathrm{N}) \text { breath } \\
\nu_{\text {as }}\left(\mathrm{PO}_{4}\right)^{3-} \mathrm{Q}^{1}\end{array}$ \\
\hline $813 \mathrm{w}$ & 828 & 828 br & $\begin{array}{l}\rho(\mathrm{Nb}-\mathrm{O}-\mathrm{Nb}) \\
\varphi(\mathrm{C}-/ \mathrm{H})\end{array}$ \\
\hline $763 \mathrm{~m}$ & & 764 & $\delta(\mathrm{C}-\mathrm{C}, \mathrm{C}-\mathrm{N})$ \\
\hline $613 m$ & 615 & $615 \mathrm{br}$ & $\begin{array}{l}\delta(\mathrm{Nb}-\mathrm{O}-\mathrm{Nb}) \\
\delta(\mathrm{C}-\mathrm{C}, \mathrm{C}-\mathrm{N})\end{array}$ \\
\hline
\end{tabular}

$\mathrm{vs}=$ very strong; $\mathrm{s}=$ strong; $\mathrm{m}=$ medium; $\mathrm{w}=$ weak; $\mathrm{vw}=$ very weak; br = broad; ir = inter-ring; $\nu=$ stretching.

$\nu_{\mathrm{s}}=$ symmetric stretching: $\nu_{\text {as }}=$ anti-symmetric stretching; $\delta=$ in-plane bending; $\varphi=$ out of plane bending. concentration of the bpy used as a molecular probe.

Fig. 6 shows the SERS spectrum of bpy $\left(10^{-6} \mathrm{M}\right)$ adsorbed on the metallic surface of the PNN2-Ag glass together with the Raman spectra of PNN2 glass and bpy in the solid state. This SERS bands at 1482, 1304 and 1059, 1009 and $764 \mathrm{~cm}^{-1}$, assigned to in-plane normal modes, suggest the ring planes are perpendicular to the surface. The Raman band at $996 \mathrm{~cm}^{-1}$, assigned to the breathing mode is shifted to $1009 \mathrm{~cm}^{-}$ ${ }^{1}$ in the SERS spectrum, that together the enhancement of the band at $764 \mathrm{~cm}^{-1}$, assigned to in-plane deformation of C-C, C-N modes, indicating the coordination involving nitrogen atoms with the silver from the surface takes place [25]. Such changes in the spectral patterns, together with the upshift of two Raman bands from 1300 and $1044 \mathrm{~cm}$ 1 , to 1304 and $1059 \mathrm{~cm}^{-1}$, respectively, are evidence of the chemical interaction of the adsorbate with the metallic surface with the formation of a surface complex $[45,46]$ (Table 2).

\section{Conclusions}

SERS is an extremely useful method to detect adsorbed molecules which are covalently bonded to the metallic Ag-NP by the formation of superficial coordinated complexes. The synthesis of Ag-NPs on PNN glasses prepared by $\mathrm{Ag}^{+} / \mathrm{Na}^{+}$ion-exchange followed by heat treatment was a high-efficient SERS-active substrate for low concentrated molecular detection. The LSPR transition of Ag nanostructures embedded in PNN glasses shows a strong dependence with the temperature and annealing time, since only the samples obtained at short annealing time produces small Ag-NP while long annealing induces the continuation of $\mathrm{Ag}^{+}$diffusion inside to the glass volume together its evaporation, hampering the aggregation and formation fair concentration of Ag-NP. This suggestion was proven by TEM images and SAED patterns, which show a homogeneous distribution of spherical Ag-NP only for PNN2-Ag samples. Atomic force microscopy (AFM) image for the PNN2-Ag sample showed a homogeneous distribution of Ag clusters over the glass surface. The SERS signal of bpy was enhanced by the Ag-NP surfaces embedded in PNN2- Ag substrate, allowing the detection at the concentration of $10^{-6} \mathrm{M}$. Therefore, we assume that PNN2-Ag glass can be used as sensor substrate for SERS applications.

\section{Acknowledgments}

The authors acknowledge, grants numbers from São Paulo Research Foundation - FAPESP (2016/16900-9 and 2013/07793-6), CAPES, and CNPq (502391/2014-6) for financial support. The authors especially thanks Dr. Marina Magnani from the Institute of Chemistry of São Paulo State University for the AFM images.

\section{References}

[1] M. Pelton, J. Aizpurua, G. Bryant, Metal-nanoparticle plasmonics, Laser Photon. Rev. 2 (3) (2008) 136-159.

[2] D. Manzani, J.M.P. Almeida, M. Napoli, L. De Boni, M. Nalin, C.R.M. Afonso, 
S.J.L. Ribeiro, C.R. Mendonça, Nonlinear optical properties of tungsten Lead-Pyrophosphate glasses containing metallic copper nanoparticles, Plasmonics 8 (2013) 1667-1674.

[3] X.M. Zhang, J.J. Han, Q. Zhang, F.F. Qin, J.J. Xiao, Plasmonic supermodes in nanocrescent dimer with tunable resonances at the near-infrared, Opt. Commun. 325 (2014) 9-14.

[4] P. Kumar, M.C. Mathpal, A.K. Tripathi, J.P.A. Agarwal, M.M. Ahmada, H.C. Swartc, Plasmonic resonance of Ag nanoclusters diffused in soda-lime glasses, Phys. Chem. Chem. Phys. 17 (2015) 08596.

[5] D. Cialla, S. Pollok, C. Steinbrücker, K. Weber, J. Popp, SERS-based detection of biomolecules, Nanophotonics 3 (6) (2014) 383-411.

[6] R. Li, J. Yang, J. Han, J. Liu, M. Huang, Quantitative determination of melamine in milk using Ag nanoparticle monolayer film as SERS substrate, Physica E 88 (2017) 164-168.

[7] M.K. Gregas, J.P. Scaffidi, B. Lauly, T. Vo-Dinh, Surface-enhanced Raman scattering detection and tracking of nanoprobes: enhanced uptake and nuclear targeting in single cells, Appl. Spectrosc. 64 (8) (2010) 858-866.

[8] S.-W. Baek, G. Park, J. Noh, C. Cho, C.-H. Lee, M.-K. Seo, H. Song, J.-Y. Lee, Au@Ag core-shell nanocubes for efficient plasmonic light scattering effect in low bandgap organic solar cells, ACS Nano 8 (4) (2014) 3302-3312.

[9] B. Sharma, R.R. Frontiera, A.-I. Henry, E. Ringe, R.P. Van Duyne, SERS: materials, applications, and the future, Mater. Today 15 (2012) 16-25.

[10] W.A. Pisarski, L. Zur, T. Goryczka, M. Sołtys, J. Pisarska, Structure and spectroscopy of rare earth - doped lead phosphate glasses, J. Alloy Compd. 587 (2014) 90-98.

[11] A.L.F. Novais, N.O. Dantas, I. Guedes, M.V.D. Vermelho, Spectroscopic properties of highly Nd-doped lead phosphate glass, J. Alloy Compd. 648 (2015) 338-345.

[12] Ch. Basavapoornima, K. Linganna, C.R. Kesavulu, S. Ju, B.H. Kim, W.-T. Han, C.K. Jayasankar, Spectroscopic and pump power dependent upconversion studies of $\mathrm{Er}^{3+}$-doped lead phosphate glasses for photonic applications, J. Alloy Compd. 699 (2017) 959-968.

[13] S. Abalde-Cela, P. Aldeanueva-Potel, C. Mateo-Mateo, L. Rodríguez-Lorenzo, R.A. Alvarez-Puebla, L.M. Liz-Marzán, Surface-enhanced Raman scattering biomedical applications of plasmonic colloidal particles, J. R. Soc. Interface 7 (2010) 435-450.

[14] S.L. Kleinman, E. Ringe, N. Valley, K.L. Wustholz, E. Phillips, K.A. Scheidt G.C. Schatz, R.P. Van Duyne, Single-molecule surface-enhanced raman spectroscopy of crystal violet isotopologues: theory and experiment, J. Am. Chem. Soc. 133 (2011) 4115-4122.

[15] E.C. Le Ru, M. Meyer, P.G. Etchegoin, Proof of single-molecule sensitivity in surface-enhanced raman scattering (SERS) by means of a two-analyte technique, J. Phys. Chem. B 110 (2006) 1944-1948.

[16] N.P.W. Pieczonka, G. Moula, R.F. Aroca, SERRS for single-molecule detection of dye-labeled phospholipids in langmuir-blodgett monolayers, Langmuir 25 (2009) $11261-11264$

[17] M. Fleischmann, P.J. Hendra, A.J. McQuillan, Raman spectra of pyridine adsorbed at a silver electrode, Chem. Phys. Lett. 26 (1974) 163-166.

[18] E.C. Le Ru, S.A. Meyer, C. Artur, P.G. Etchegoin, J. Grand, P. Lang, F. Maurel, Experimental demonstration of surface selection rules for SERS on flat metallic surfaces, Chem. Commun. 47 (2011) 3903-3905.

[19] E.C. Le Ru, E. Blackie, M. Meyer, P.G. Etchegoin, Surface-enhanced raman scat tering enhancement factors: a comprehensive study, J. Phys. Chem. C 111 (37) (2007) 13794-13803.

[20] B. Sharma, M.F. Cardinal, S.L. Kleinman, N.G. Greeneltch, R.R. Frontiera, M.G. Blaber, G.C. Schatz, R.P. Van Duyne, High-performance SERS substrates: advances and challenges, MRS Bull. 38 (2013) 615-624.

[21] X. Liu, M. Knauer, N.P. Ivleva, R. Niessner, C. Haisch, Synthesis of core-shell surface-enhanced raman tags for bioimaging, Anal. Chem. 82 (2010) 441-446.

[22] S.J. Cho, Y. Ahn, K.K. Maiti, U.S. Dinish, C.Y. Fu, P. Thoniyot, M. Olivo, Y. Chang, Combinatorial synthesis of a triphenylmethinelibrary and their application in the development of surface enhanced raman scattering (SERS) probes, Chem. Commun. 46 (2010) 722-724.

[23] Y. Ye, H. Liu, L. Yang, J. Liu, Sensitive and selective SERS probe for trivalen chromium detection using citrate attached to gold nanoparticles, Nanoscale 4 (2012) 6442-6448.

[24] E.M. McMahon, Y. Wang, L.J. Sherry, R.P.V. Duyne, L.D. Marks, S.K. Gray, G.C. Schatz, Optical spectra, and electrodynamics of single silver nanocubes, J. Phys. Chem. C 113 (2009) 2731-2735.

[25] A.G. Brolo, Z. Jiang, D.E. Irish, The orientation of 2,2-bipyridine adsorbed at a SERS-active Au(111) electrode surface, J. Electroanal. Chem. 547 (2003) 163-172.

[26] S. Welter, K. Brunner, J.W. Hofstraat, L. De Cola, Electroluminescent device with reversible switching between red and green emission, Nature 421 (2003) 54-57.

[27] R.F. Khairutdinov, J.K. Hurst, Cyclic transmembrane charge transport by pyrylium ions in a vesicle-based photocatalytic system, Nature 402 (1999) 509-511.

[28] J. Schnadt, P.A. Bruhwller, L. Patthey, J.N. O'Shea, S. Sodergren, M. Odellus, R. Ahuja, O. Karis, M. Bassler, P. Persson, H. Slegbahn, S. Lunell, N. Matensson, Experimental evidence for sub-3-fs charge transfer from an aromatic adsorbate to a semiconductor, Nature 418 (2002) 620-623.

[29] M.A. Khan, D.G. Tuck, The structure of (2,2'-bipyridine)dichlorozinc(II), Zn $\left(\mathrm{C}_{10} \mathrm{H}_{8} \mathrm{~N}_{2}\right) \mathrm{Cl}_{2}$, Acta Crystallogr. C40 (1984) 60-62.

[30] A. Simo, J. Polte, N. Pfänder, U. Vainio, F. Emmerling, K. Rademann, Formation mechanism of silver nanoparticles stabilized in glassy matrices, J. Am. Chem. Soc. 134 (45) (2012) 18824-18833.
[31] A. Simo, V. Joseph, R. Fenger, J. Kneipp, K. Rademann, Long-term stable silver subsurface ion-exchanged glasses for SERS applications, ChemPhysChem 12 (2011) 1683-1688.

[32] Y.H. Wang, S.J. Peng, J.D. Lu, R.W. Wang, Y.L. Mao, Y.G. Cheng, Optical properties of $\mathrm{Cu}$ and $\mathrm{Ag}$ nanoparticles synthesized in glass by ion implantation, Vacuum 83 (2) (2008) 408-411.

[33] J.M.P. Almeida, P.H.D. Ferreira, D. Manzani, M. Napoli, S.J.L. Ribeiro, C.R. Mendonça, Metallic nanoparticles grown in the core of femtosecond laser micromachined waveguides, J. Appl. Phys. 115 (2014) 193507.

[34] B. Akkopru, C. Durucan, Preparation and microstructure of sol-gel derived silverdoped silica, J. Sol-Gel Sci. Technol 43 (2) (2007) 227-236.

[35] Y. Chen, L. Karvonen, A. Säynätjoki, C. Ye, A. Tervonen, S. Honkanen, Ag nanoparticles embedded in glass by two-step ion exchange and their SERS application, Opt. Mat. Express 1 (2) (2011) 164-172.

[36] S.S. Kistler, Stresses in glass produced by nonuniform exchange of monovalent ions, J. Am. Ceram. Soc. 45 (1962) 59-68.

[37] M.E. Nordberg, E.L. Mochel, H.M. Garfinkel, J.S. OIcott, Strengthening by ion exchange, J. Am. Ceram. Soc. 47 (1964) 215-219.

[38] Corning Glass Works, Method of making a glass article of high mechanical strength and article made thereby, US patent 2779136 (1960)

[39] G. Chartier, P. Coller, A. Guez, P. Jaussaud, Y. Won, Graded-index surface or buried waveguides by ion exchange in glass, Appl. Opt. 19 (1980) 1092-1095.

[40] G. McNay, D. Eustace, W.E. Smith, K. Faulds, D. Graham, Surface-enhanced Raman scattering (SERS) and surface-enhanced resonance Raman scattering (SERRS): a review of applications, Appl. Spectrosc. 65 (8) (2011) 825-837.

[41] D. Manzani, T. Gualberto, J.M.P. Almeida, M. Montesso, C.R. Mendonça, V.A.G. Rivera, L. De Boni, M. Nalin, S.J.L. Ribeiro, Highly nonlinear $\mathrm{Pb}_{2} \mathrm{P}_{2} \mathrm{O}_{7}-\mathrm{Nb}_{2} \mathrm{O}_{5}$ glasses for optical fiber production, J. Non-Cryst. Solids 443 (2016) 82-90.

[42] D. Manzani, R.G. Fernandes, Y. Messaddeq, S.J.L. Ribeiro, F.C. Cassanjes, G. Poirier Thermal, structural and optical properties of new tungsten lead-pyrophosphate glasses, Opt. Mater. 33 (2011) 1862-1866.

[43] K.L. Kelly, E. Coronado, L.L. Zhao, G.C. Schatz, The optical properties of metal nanoparticles: the influence of size, shape, and dielectric environment, J. Phys. Chem. B 107 (3) (2003) 668-677.

[44] J.R. Qiu, X.W. Jiang, C.S. Zhu, M. Shirai, J. Si, N. Jiang, K. Hirao, Manipulation of gold nanoparticles inside transparent materials, Angew Chem Int 43 (17) (2004) 2230-2234.

[45] Y. Yuan, Y. Liu, M. Xu, J. Yao, R. Gu, The surface adsorption of 2,2-bipyridine and benzoin on $\mathrm{Cu}$ electrode interface probed by surface-enhanced raman spectroscopy, J. Electroanal. Chem. 726 (2014) 44-50.

[46] A.C. Sant'Ana, W.A. Alves, R.H.A. Santos, A.M.D.C. Ferreira, M.L.A. Temperini, The absorption of 2,2':6', 2 “'-terpyridine, 4'-(5-mercaptopentyl)-2,2':6',1"-terpyridinyl, and perchlorate on silver and copper surfaces monitored by SERS, Polyhedron 22 (2003) 1673-1682.

[47] A.J. Barbosa, F.A. Dias Filho, L.J.Q. Maia, Y. Messaddeq, S.J.L. Ribeiro, R.R. Gonçalves, $\mathrm{Er}^{3+}$ doped phosphoniobate glasses and planar waveguides: structural and optical properties, J. Phys.: Condens. Matter 20 (2008) 285224

[48] E.A. Coronado, E.R. Encina, F.D. Stefani, Optical properties of metallic nanoparticles: manipulating light, heat and forces at the nanoscale, Nanoscale 10 (2011) 4042-4059.

Danilo Manzani is a professor of Department of Chemistry and Molecular Physics at the São Carlos Institute of Chemistry of the University of São Paulo-USP, Brazil. His current researches are focused on the material chemistry of optical glass for applications in photonics, optical sensing, and glass spectroscopy.

Douglas Faza Franco is a post-doctorate fellow of the Institute of Chemistry of the São Paulo State University-UNESP, Brazil. His current research interests are the development and synthesis of specialty magneto-optical glasses and fibers.

Conrado R. M. Afonso is a professor of Department of Material Engineering at the Federal University of São Carlos-UFSCar, Brazil. Has experience of around 20 years in electron microscopy, acting on amorphous phase, spray forming, microstructural characterization.

Antônio C. Sant'Ana is a professor of Federal University of Juiz de Fora-UFJF. His current research interests are on the investigation of molecular adsorption on $\mathrm{Au}, \mathrm{Ag}$ and $\mathrm{Cu}$ nanostructured surfaces and analysis by Raman spectroscopy and SERS.

Marcelo Nalin is an assistant professor of the Institute of Chemistry of the São Paulo State University-UNESP, Brazil. His current research interests are on chemistry and physics of glass, glass-ceramics, magneto-optical and photosensitive materials.

Sidney J. L. Ribeiro is a full professor of the Institute of Chemistry of the São Paulo State University-UNESP, Brazil. His current research interests are on inorganic chemistry and their implications on materials science, spectroscopy and chemistry education. He was visiting professor at the University of Trento, Italy, Universities of Anger, Toulouse and Bordeaux, France, University of Aveiro, Portugal, and Federal University of Juiz de Fora, Brazil. 